\title{
The Study of Approaches to Promote Induced Draft Fans with Adjustable Guide Vanes into Ones with Adjustable Rotor Blades in Power Unit of 600MW
}

\author{
Zhengsheng Chen ${ }^{1}$, Jin Zheng ${ }^{2}{ }^{*}$, Dawei Sun ${ }^{2}$, Kailun Li $^{2}$ \\ ${ }^{1}$ Gui Zhou Xineng Electric Power Construction Co., Ltd., Guiyang, China \\ ${ }^{2}$ Xi' an Thermal Power Research Institute Co., Ltd., Xi' an, China \\ Email address: \\ zhengjin@tpri.com.cn (Jin Zheng), sundawei@tpri.com.cn (Dawei Sun), li.kailun@qq.com (Kailun Li) \\ ${ }^{*}$ Corresponding author
}

To cite this article:

Zhengsheng Chen, Jin Zheng, Dawei Sun, Kailun Li. The Study of Approaches to Promote Induced Draft Fans with Adjustable Guide Vanes into Ones with Adjustable Rotor Blades in Power Unit of 600MW. International Journal of Energy and Power Engineering.

Vol. 8, No. 2, 2019, pp. 12-17. doi: 10.11648/j.ijepe.20190802.11

Received: January 14, 2019; Accepted: April 16, 2019; Published: June 5, 2019

\begin{abstract}
In order to figure out stall solution of induced draft fans (IDFs) in power plants, the stall reason of IDFs with guide vanes in Tongchuan Power Plant of 600MW is investigated. By comparing hot test data of IDFs, we also find that the IDFs are of low efficiency and high power consumption in addition to the stall problem. Considering the above condition of the IDFs, two reasonable approaches are proposed to prevent stall and reduce power consumption of IDFs. With the hot test of reformation results, it is found that the reformation scheme of IDFs with adjustable rotor blades is much better with higher efficiency and safer characteristics. The work in this study has great significance and also provides practicable ways for stall-preventing, energy-saving and cost-reducing of power plants.
\end{abstract}

Keywords: Power Plant Fans, Stall-preventing, Energy-saving and Cost-reducing, Reform Project

\section{Introduction}

Huaneng Tongchuan No.1 and No.2 Power Plants in China, originally equipped axial induced draft fans (IDFs) with adjustable guide vanes, are coal-fired generating units of $600 \mathrm{MW}$. The IDFs have had lower generating loads from its earlier operation. It is also found that the operating efficiency of IDFs is in lower level. The phenomenon of lower efficiency and insufficient stall margin exists extensively for axial IDFs with adjustable guide vanes, which reduces the safety and efficiency of power plants.

Based on the above situations, a lot of energy saving studies have been carried out. In 2007, with a view to improving the operation performance of power station fans, Liu Jiayu [1] brought forward a specific method, which focused on the economy and reliability of variable speed regulation of fans with frequency converter. In 2010, the energy-saving and stall diagnosis on IDFs in Huaneng Tongchuan power plant was conducted by Zheng Jin [2] through experiments, and corresponding reformation scheme was also proposed for attaining the goal of energy saving and stall preventing. Some theoretical and practical research, in which a series of technologies and measures on reducing energy consumption and increasing efficiency of fans were proposed, was also conducted by Liu Jiayu et al [3], In 2010, MA Kunxiang et al. [4] conducted the research on the implementation of energy saving scheme for axial fans with adjustable rotor blades in $330 \mathrm{MW}$ generating units. The energy saving reformation methods of axial fans were discussed in details. Later in 2015, Liu Jiayu made a further study on energy conservation technology of air and flue gas system, in which many useful strategies and methods are presented. [5]

On the other side, safe operation and stall preventing of fans are also very important for power plant. As early as in 2000 and 2002, DUAN Tiecheng [6] and HUA Guojun [7] studied countermeasures of stall and surge of power station fans. It was found that axial fans with adjustable rotor blades had better anti-stall abilities and worked more efficiently than 
those with adjustable guide vanes. In 2008, Li Chunhong [8] made more detailed research on the strategy to prevent stall and surge, in which many applicable theories and methods were presented. Later in 2009, stall and surging phenomenon of IDFs in 300MW Unit were analyzed by Huang Wei [9]. It was found that operating points of fans falling into unstable working area due to unreasonable selection was the main reason of stall. Finally, practical operation method was proposed to ensure the safety and efficient operation of IDFs. In the same year, FENG Xiaojie [10] studied and found that optimizing operation of power station fans were able to make the fans operate efficiently and safely.

Furthermore, with the development of environmental protection and energy-saving policy in China, a lot of axial fans with adjustable vanes need to be reformed for higher pressure, higher efficiency and better anti-stall performance. It is found and verified that axial fans with adjustable rotor blades are more efficient and have better anti-stall performance than axial fans with adjustable guide vanes [11-13]. The reason is that axial fans with adjustable guide vanes are usually meridionally accelerated with higher pressure and lower efficiency, but axial fans with adjustable rotor blades are usually meridionally constant with lower pressure and higher efficiency. What's more, axial fans with adjustable rotor blades have better anti-stall capability than those with adjustable guide vane due to their aerodynamic performance [14-15]. As mentioned above, axial fans with adjustable guide vanes usually have higher pressure, so axial fans with adjustable rotor blades equipped with 2-stage rotors are able to match the pressure capacity of axial fans with adjustable guide vanes equipped with 1-stage rotors. So more and more 1-stage axial fans with adjustable guide vanes have been reformed into 2-stage axial fans with adjustable rotor blades for higher pressure, higher efficiency and better anti-stall performance.

For more references about reformation of power station fans due to stall preventing and energy saving, please refer to published papers [16-18]. Because the reformation of power station fans for energy saving and stall preventing is a research topic with Chinese characteristics, there is not so much research conducted by international scholars. The international progress about this research topic cannot be presented due to current situation.

From the above studies, it can be found that a lot of research results of energy-saving and stall-preventing for power station fans have been presented. However, not so many studies are done on engineering cases of fan reconstruction or reformation for $600 \mathrm{MW}$ or even more large-scale power plant. The description of reconstruction or reformation scheme is not clearly given. For this reason, two feasible solutions, the reformation schemes of IDFs with guide vanes and the one with adjustable rotor blades are offered to solve stall problem and improve efficiency. Through the final reconstruction results, it was found that reformation scheme of IDFs with adjustable rotor blades worked well on satisfying the needs in solving stall problem, improving operating efficiency and reducing power consumption significantly.

\section{Basic Parameters of Power Plant}

Huaneng Tongchuan Power Plant No.1 and No.2 Units are Turbo-generator units of 600MW. Boiler of HG-2070/17.5-YM9 is designed and manufactured by Harbin boiler plant using technology imported from $\mathrm{ABB} \mathrm{CE}$ Combustion Company. The boiler is of sub-critical parameters, primary intermediate reheat, control circulation, four-corner round combustion mode, single furnace balanced ventilation, solid dry slag discharge, open air arrangement, П-shaped steam drum furnace with all-steel frame. The ventilation system of the boiler is equipped 2 axial primary air fans with adjustable rotor blades, 2 axial force draft fans with adjustable rotor blades, and 2 IDFs with adjustable guide vanes. The IDFs are manufactured by Shanghai blower factory co., LTD.

Table 1. Design parameters of IDFs.

\begin{tabular}{llll}
\hline Parameters & Units & TB (Test Block) Point & BMCR (Boiler maximum continuous rating) Working Condition \\
\hline Inlet flow rate & $\left(\mathrm{m}^{3} \cdot \mathrm{s}^{-1}\right)$ & 565 & 495 \\
Inlet temperature & ${ }^{\circ} \mathrm{C}$ & 125.8 & 113.9 \\
Inlet density & $\left(\mathrm{kg} \cdot \mathrm{m}^{-3}\right)$ & 0.834 & 0.859 \\
Fan total pressure & $\mathrm{Pa}$ & 5131 & 3950 \\
Fan efficiency & $\%$ & 81.93 & 80.13 \\
Fan shaft power & $\mathrm{kW}$ & 3467 & 2402 \\
Fan speed & $\mathrm{r} \cdot \mathrm{min}^{-1}$ & 590 & \\
Motor rated power & $\mathrm{kW}$ & 3650 & \\
Motor rated voltage & $\mathrm{kV}$ & 6 & \\
Motor rated current & $\mathrm{A}$ & 432 & \\
Motor speed & $\mathrm{r} \cdot \mathrm{min}^{-1}$ & 597 & \\
\hline
\end{tabular}

\section{Analysis of Fan Hot Test Data}

In order to get basic data for reformation project of IDFs, hot test of IDFs was carried out by Thermal Power Research Institute. Since the equipment type of Unit No.1 and Unit No. 2 are identical, and the IDFs problems are same with each other, the hot test was mainly carried out on IDFs of Unit
No.1.

Fan hot test method and calculation method are based on DL/T469-2004 "Field performance test of power station boiler fans". According to operating conditions of the power unit, the hot test was conducted on three operating conditions of $600 \mathrm{MW}, 480 \mathrm{MW}$ and $380 \mathrm{MW}$. The experimental data and results are shown in Table 2 and the characteristic 
performance curve of IDFs is shown in Figure 1.

As seen in Figure 1, the operating points of fans on $600 \mathrm{MW}$ are far away from the stall line, but the deviation of two IDFs increases as power generating load decreases, and stall occurs when power generating load is below $380 \mathrm{MW}$.

Considering the safety of IDFs, the opening of 1A IDF is increased intentionally to make the two IDFs operate differently. From Figure 1, it is seen that as the power generating load decreases, the operating condition of 1B IDF falls into the stall region [19].

Combined with Table 2 and Figure 1, it is seen that the opening of IDFs is only $50.0 \%$ on $600 \mathrm{MW}$ (angle of adjustable guide vanes is $-18.5^{\circ}$ on the performance curve). The angle of adjustable guide vanes of TB (Test Block) point is corresponding to $+20^{\circ}$ on the performance curve, that means the IDFs still have $38.5^{\circ}$ angle margin on $600 \mathrm{MW}$. It is concluded that the IDF performance does not match the flue system.

In Figure 1, it is seen that the resistance line of flue network is located in the lower region of the performance curve and the efficiency of IDFs is only $77 \%$ on average of $600 \mathrm{MW}$. As generating load decreases, the efficiency of IDFs decreases rapidly than flow rate and pressure, so the efficiency of IDFs is only $54 \%$ of $380 \mathrm{MW}$.

Based on the above analysis, it is seen that main stall reason is the mismatch of IDFs and its flue network resistance, which causes lower efficiency and stall phenomenon of IDFs.

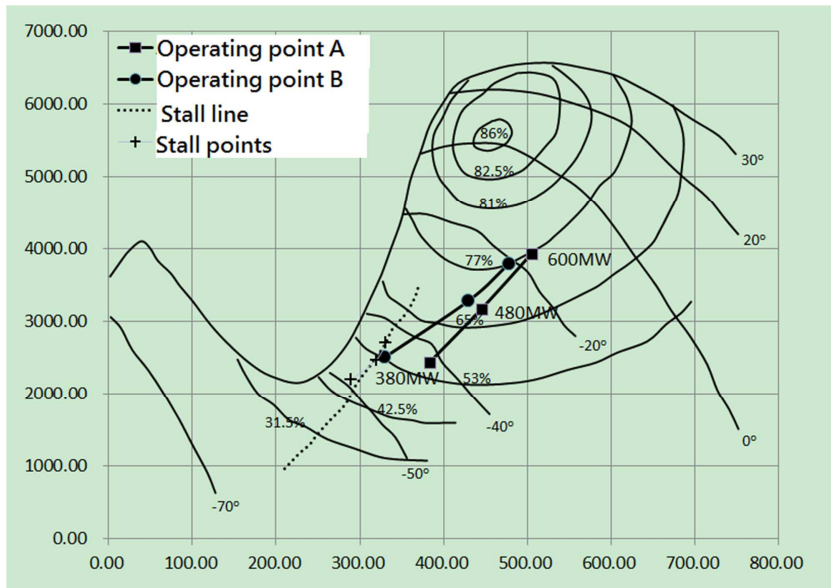

Figure 1. Performance curve and operating points of IDFs.

Table 2. Key data of hot test of IDFs.

\begin{tabular}{|c|c|c|c|c|c|c|c|}
\hline Items & Units & Content & & & & & \\
\hline Generating condition & MW & 598.1 & 597.3 & 475.8 & 475.8 & 380.0 & 380.0 \\
\hline Boiler duty & $\mathrm{t}^{-h^{-1}}$ & 1893.8 & 1886.5 & 1529.2 & 1463.4 & 1152.3 & 1152.3 \\
\hline Measured fan flow rate & $\mathrm{m}^{3} \cdot \mathrm{s}^{-1}$ & 489.9 & 463.3 & 431.1 & 422.7 & 374.3 & 325.9 \\
\hline Measured fan specific work & J. $\mathrm{kg}^{-1}$ & 3809.0 & 3723.9 & 3021.5 & 3137.1 & 2366.9 & 2355.4 \\
\hline Measured fan efficiency & $\%$ & 80.6 & 78.9 & 70.0 & 75.8 & 59.4 & 51.4 \\
\hline Fan opening in control room & $\%$ & 68.4 & 55.9 & 62.4 & 54.6 & 55.0 & 45.7 \\
\hline Fan opening on performance curve ${ }^{2}$ & $\%$ & 51.5 & 48.5 & 38.8 & 38.8 & 27.2 & 25.2 \\
\hline
\end{tabular}

\section{Comparison of Reformation Schemes}

Based on the above analysis and the actual situation, in order to solve the problem, the most fundamental method is to reform the existing IDFs.

\subsection{Scheme I: Local Reformation of Original IDFs}

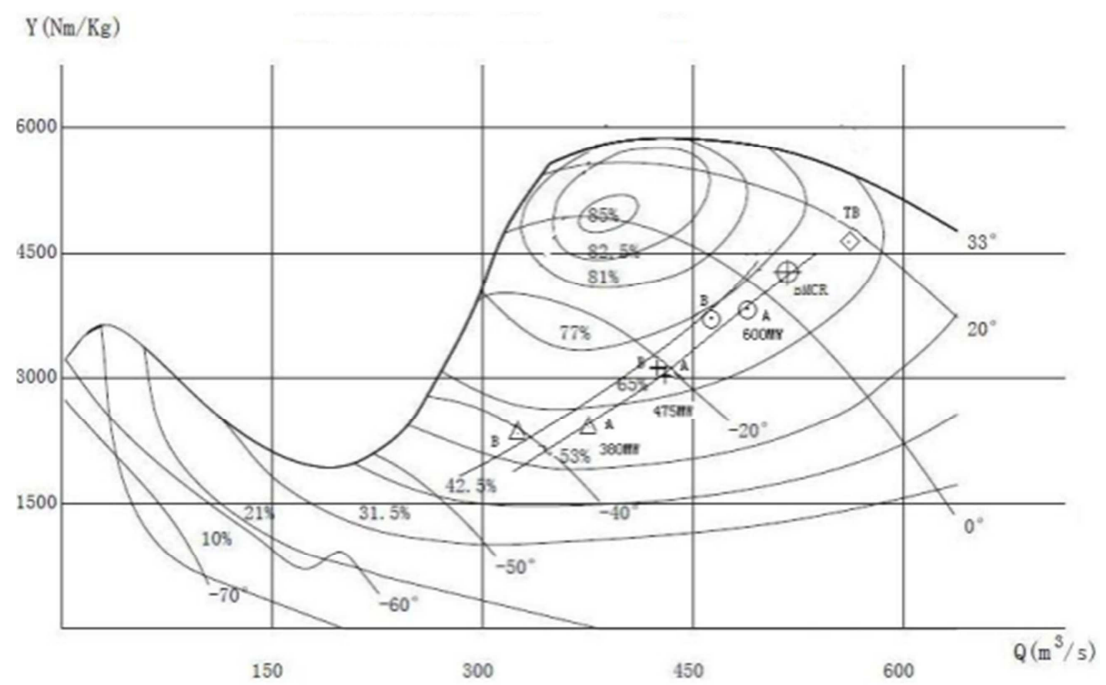

Figure 2. Performance curve and operating points of IDFs before and after reformation with Scheme I. 
The type of original IDFs is G158/363 with a rotating speed of $590 \mathrm{r} / \mathrm{min}$. According to the actual situation, the feasible reformation scheme is to replace the IDFs impeller as $\mathrm{G} 158 / 343$. It is noticed that G158/363 and G158/343 are different types of axial fans with adjustable guide vanes, and the latter one has better aerodynamic performance than the former one.

According to the reform procedure, the impeller need to be replaced, the main case, the stator (rear guide vanes) group, and the necessary transition section of the interface need to be reformed. The fan base, motor, transmission group, inlet box and diffuser remain unchanged. The operating points, BMCR (Boiler maximum continuous rating) point and new TB (Test Block) point on performance curve are shown in Figure 2. Effects comparison of IDFs (before and after the reformation) is listed in Table 2. According to the location of each operating point in Figure 2, scheme I can solve the stall problem of IDFs and has energy saving function.

Table 3. Effects comparison of IDFs before and after reformation with Scheme I.

\begin{tabular}{|c|c|c|c|c|c|c|c|}
\hline \multirow{2}{*}{$\frac{\text { Items }}{\text { Unit load }}$} & \multirow{2}{*}{$\begin{array}{l}\text { Units } \\
M W\end{array}$} & \multicolumn{2}{|c|}{ Working condition 1} & \multicolumn{2}{|c|}{ Working condition 2} & \multicolumn{2}{|c|}{ Working condition 3} \\
\hline & & 598.1 & 597.3 & 475.8 & 475.8 & 380.0 & 380.0 \\
\hline Boiler duty & $\mathrm{t} \cdot \mathrm{h}^{-1}$ & 1893.8 & 1886.5 & 1529.2 & 1463.4 & 1152.3 & 1152.3 \\
\hline Fan number & l & $\mathrm{A}$ & $\mathrm{B}$ & A & $\mathrm{B}$ & A & $\mathrm{B}$ \\
\hline Fan power & $\mathrm{kW}$ & 1611.2 & 1497.2 & 1160.6 & 1173.8 & 783.5 & 681.1 \\
\hline Electric efficiency & $\%$ & 94 & 93.8 & 93.3 & 93 & 92.2 & 92.2 \\
\hline Fan efficiency & $\%$ & 77 & 77 & 67 & 69 & 55 & 53 \\
\hline Angle on curve & $\circ$ & -17 & -20 & -30 & -30 & -42 & -44 \\
\hline Motor input power & $\mathrm{kW}$ & 2226.0 & 2072.9 & 1856.6 & 1829.2 & 1545.1 & 1393.8 \\
\hline \multicolumn{8}{|c|}{ Scheme I: Local reformation of original IDFs } \\
\hline Fan efficiency (after reformation) & $\%$ & 75 & 74 & 69 & 71 & 61 & 59 \\
\hline Opening on curve (after reformation) & $\circ$ & -5 & -10 & -21 & -21 & -33 & -41 \\
\hline Shaft Power (after reformation) & $\mathrm{kW}$ & 2148 & 2023 & 1682 & 1653 & 1284 & 1154 \\
\hline Motor input power (after reformation) & $\mathrm{kW}$ & 2285.4 & 2157.0 & 1802.8 & 1777.7 & 1393.1 & 1252.1 \\
\hline Fan efficiency increased & $\%$ & -2 & -3 & 2 & 2 & 6 & 6 \\
\hline Electricity saved per year & kW.h & 511200.0 & & & & & \\
\hline Cost saving per year & $10^{4}$ Yuan & 15.3 & & & & & \\
\hline
\end{tabular}

\subsection{Scheme II: Promoting Original IDFs into Ones with Adjustable Rotor Blades}

In Scheme II, fan basis, motor, transmission group, inlet box, and diffuser are going to kept unchanged. Original fan rotors are replaced as SAF37.5-23.7-1. It is noticed that SAF37.5-23.7-1 are one type of axial fans with adjustable rotor blades, and it has better aerodynamic performance than axial fans with adjustable guide vanes.

According to the reform procedure, main case and stator group (rear guide vanes) are going to be reformed. Namely, inlet adjustable vanes are going to be dismantled; inlet nozzle, shaft and bearing box are newly added at the same time. The operating points of IDFs on performance curve after reformation are shown in Figure3. It is found that the stall margin and safety of fans are enhanced, and the fan efficiency is increased after reformed by scheme II. Effects comparison of IDFs is listed in Table 2.

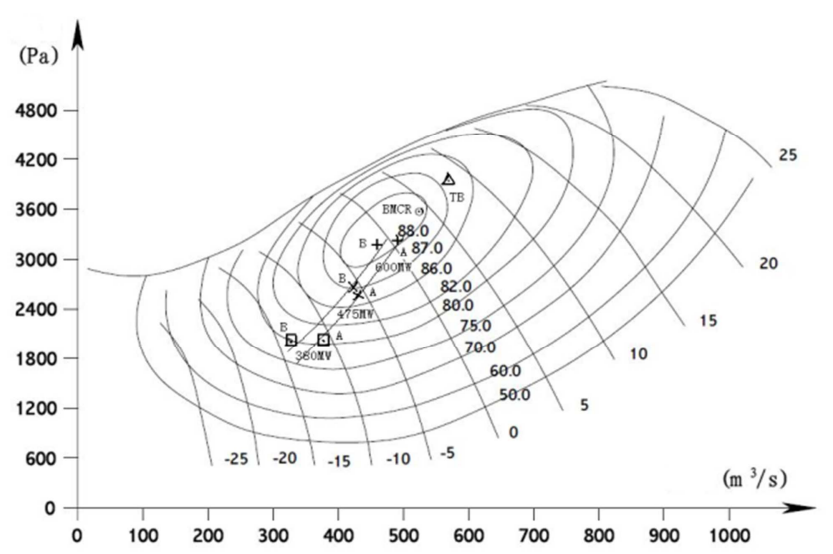

Figure 3. Performance curve and operating points of IDFs before and after reformation with Scheme II.

Table 4. Effects comparison of IDFs before and after reformation with Scheme II.

\begin{tabular}{|c|c|c|c|c|c|c|c|}
\hline \multirow{2}{*}{$\begin{array}{l}\text { Items } \\
\text { Unit load }\end{array}$} & \multirow{2}{*}{$\begin{array}{l}\text { Units } \\
M W\end{array}$} & \multicolumn{2}{|c|}{ Working condition 1} & \multicolumn{2}{|c|}{ Working condition 2} & \multicolumn{2}{|c|}{ Working condition 3} \\
\hline & & 598.1 & 597.3 & 475.8 & 475.8 & 380.0 & 380.0 \\
\hline Boiler duty & t.h $\mathrm{h}^{-1}$ & 1893.8 & 1886.5 & 1529.2 & 1463.4 & 1152.3 & 1152.3 \\
\hline Fan number & l & A & $\mathrm{B}$ & A & $\mathrm{B}$ & A & $\mathrm{B}$ \\
\hline Fan power & $\mathrm{kW}$ & 1611.2 & 1497.2 & 1160.6 & 1173.8 & 783.5 & 681.1 \\
\hline Motor power & $\%$ & 94 & 93.8 & 93.3 & 93 & 92.2 & 92.2 \\
\hline Fan efficiency & $\%$ & 77 & 77 & 67 & 69 & 55 & 53 \\
\hline Shaft power & $\mathrm{kW}$ & 2092.5 & 1944.4 & 1732.2 & 1701.2 & 1424.5 & 1285.1 \\
\hline
\end{tabular}




\begin{tabular}{|c|c|c|c|c|c|c|c|}
\hline \multirow{2}{*}{$\begin{array}{l}\text { Items } \\
\text { Scheme II: }\end{array}$} & \multirow{2}{*}{$\begin{array}{l}\text { Units } \\
\text { with adju }\end{array}$} & \multicolumn{2}{|c|}{ Working condition 1} & \multicolumn{2}{|c|}{ Working condition 2} & \multicolumn{2}{|c|}{ Working condition 3} \\
\hline & & rotor blade & & & & & \\
\hline Fan efficiency (after reformation) & $\%$ & 88 & 88 & 86 & 87 & 80 & 80 \\
\hline Shaft power (after reformation) & $\mathrm{kW}$ & 1830.9 & 1701.4 & 1349.5 & 1349.2 & 979.4 & 851.4 \\
\hline Motor input power (after reformation) & $\mathrm{kW}$ & 1947.8 & 1813.8 & 1446.4 & 1450.7 & 1062.2 & 923.4 \\
\hline Fan efficiency increased & $\%$ & 11 & 11 & 19 & 18 & 25 & 27 \\
\hline Electricity saved per hour & kW.h & 278.3 & 259.1 & 410.2 & 378.5 & 482.8 & 470.4 \\
\hline Electricity saved per year & kW.h & 4558600.0 & & & & & \\
\hline Cost saving per year & $10^{4}$ Yuan & 136.8 & & & & & \\
\hline
\end{tabular}

\subsection{Comparison of Two Schemes}

The two kinds of schemes above both can solve the stall problem of IDFs, the main difference between them is energy saving amount. For scheme I, the reformation investment is about 1.8 million Yuan, and the investment recovery period is about 11.8 years. For scheme II, the reformation investment is about 3.5 million Yuan, and the investment recovery period is about 2.6 years. Although the investment of scheme II is large, all the investment can be recovered within 3 years. The IDFs efficiency is much higher, and working points are far away from the stall line. Generally speaking, scheme II is much better than scheme I.

\section{Implementation and Evaluation of the Reformation}

Finally, Huaneng Tongchuan Power Plant chose to reform the original IDFs of Unit 2 to axial IDFs with adjustable rotor blades (Scheme II). The hot test results show that the working points of the new IDFs after reformation are far away from the stall line. The safety of the fans is greatly improved [20]. The comparison of operation efficiency, currents and input power of IDFs before and after the reformation are listed in Table 5 .

As seen in Table 5, IDFs efficiency increased by more than $18 \%$ on average after reformation. At the load of $300 \sim 330 \mathrm{MW}$, the efficiency increased by up to $32.6 \%$. The two IDFs saved about $800 \mathrm{kWh}$ per hour and power consumption rate decreased by about $0.20 \%$. The annual cost savings can reach 1.524 million Yuan. The reformation cost of IDFs for Unit 2 of Tongchuan power plant is 3.2 million Yuan in total, and the investment can be recovered in just two years.

Table 5. Operating efficiency comparison of the old and new fans.

\begin{tabular}{|c|c|c|c|c|c|c|c|}
\hline Items & Contents & & & & & & \\
\hline Fan number & Units & $\mathrm{A}$ & $\mathrm{B}$ & $\mathrm{A}$ & $\mathrm{B}$ & A & B \\
\hline Working Conditions & MW & $550 \sim 570$ & & $447 \sim 460$ & & $301 \sim 307$ & \\
\hline Boiler duty & t.h $h^{-1}$ & 1937.4 & & 1457.7 & & $949 \sim 952$ & \\
\hline Original motor currents & A & 289.0 & 291.3 & 237.1 & 238.0 & 195.7 & 198.5 \\
\hline Original motor input power & $\mathrm{kW}$ & 2262.8 & 2305.4 & 1608.9 & 1676.3 & 915.2 & 1070.9 \\
\hline Original fan efficiency & $\%$ & 71.7 & 78.3 & 64.3 & 61.7 & 44.8 & 39.1 \\
\hline Working condition & MW & 595.5 & & 453.3 & & 341.2 & \\
\hline Motor current (after reformation) & A & 257.8 & 250.5 & 200.0 & 196.0 & 183.3 & 180.3 \\
\hline Motor input power (after reformation) & $\mathrm{kW}$ & 1919.3 & 1862.2 & 1054.5 & 1020.8 & 729.8 & 712.3 \\
\hline Fan efficiency (after reformation) & $\%$ & 88.7 & 88.2 & 83.0 & 82.8 & 66.5 & 71.7 \\
\hline Efficiency enhanced & $\%$ & 17.0 & 9.9 & 18.7 & 21.1 & 21.7 & 32.6 \\
\hline Currents decreased & A & 31.2 & 40.8 & 37.1 & 42.0 & 12.4 & 18.2 \\
\hline Motor input power (after reformation) & kW.h & 343.5 & 443.2 & 554.4 & 655.5 & 185.4 & 358.6 \\
\hline Power consumption rate decreased & $\%$ & 0.20 & & & & & \\
\hline
\end{tabular}

\section{Conclusions}

Through the analysis of the test data before and after the reformation of IDFs of Unit No.2 of Huaneng Tongchuan Power Plant, it is found that by replacing the original IDFs with adjustable guide vanes, the ones with adjustable rotor blades not only fundamentally solves stall problem, but also achieves obvious energy saving effect. The average power saving of two IDFs is about $800 \mathrm{kWh}$ per hour, and the power consumption rate of the plant is about $0.20 \%$ decreased. This reformation scheme and its test analysis have reference significance for the subsequent reformation of IDFs for large thermal power plants.

\section{Acknowledgements}

Supported by Shaanxi Key Research and Development Program (No. 2018ZDXM-GY-028).

\section{References}

[1] LIU Jiayu. The discussion about energy conservation of fans in power plant in China [J]. Compressor Blower \& Fan Technology, 2007, 3(0): 50-55 (in Chinese).

[2] ZHENG Jin. Report of performance test of induced fans of №2generator unit in Huaneng Tongchuan Power Plant [R]. Xi'an: Xi'an Thermal Power Research Institute Co., Ltd. 2010: 8-15 (in Chinese). 
[3] LIU Jiayu, WANG Hong, MA Feng. The study of energy conservation technology of air and flue gas systems in power plant boiler [J]. Compressor Blower \& Fan Technology, 2013(5): 61-68 (in Chinese).

[4] MA Kunxiang, ZHENG Jin, DONG Kangtian. The study and application of energy conservation on axial flow forced fans with adjustable rotor blade [J]. Thermal Power Generation, 2010(10): 77-79(in Chinese).

[5] LIU Jiayu. The technology and method of energy conservation of power plant fans $[\mathrm{J}]$. Compressor Blower \& Fan Technology, 2015(5): 56-63 (in Chinese).

[6] HUA Guojun. The countermeasure of stall and surge on axial flow fans [J]. Zhejiang Electric Power, 2002(2): 40-43 (in Chinese).

[7] DUAN Tiecheng. The study of stall experiment and prevention of axial flow fans [J]. Northeast Electric Power Technology, 2000(11): 13-18 (in Chinese).

[8] LI Chunhong. The analysis and prevent measures of stall and surge axial flow fans [J]. Thermal Power Generation, 2008(3): 76-78 (in Chinese).

[9] HUANG Wei, XIE Guohong. The diagnosis and discussion about the stall and surge of induced fans in large-capacity boiler [J]. Power System Engineering, 2009, 25(4): 1-4(in Chinese).

[10] FENG Xiaojie. The discussion about optimizing operation of fans in power plant [J]. Generating Equipment, 2009(1): 14-16 (in Chinese).

[11] Rama S. R. Gorla, Aijaz A. Khan. Turbomachinery Design and Theory [M]. CRC Press, 2003.8: 10-125.
[12] Heinz P. Bloch. Compressors and Modern Process Applications [M]. John Wiley \& Sons, Inc. 2006.2: 45-123.

[13] Meinhard Schobeiri. Turbomachinery Flow Physics and Dynamic Performance [M]. Springer. 2004.12: 36-103.

[14] S. L. Dixon, B. Eng. Fluid Mechanics and Thermodynamics of Turbomachinery [M]. Pergamon Press Ltd. 1998: 16-97.

[15] Gordon C. Oates. Aerothermodynamics of Gas Turbine and Rocket Propulsion [M]. American Institute of Aeronautics and Astronautics, Inc., 1997.1: 53-96.

[16] WANG Yigang, JIANG Wenjun. The analysis and prevention of stall on forced fans [J]. Hunan Electric Power, 2006(3): 48-49 (in Chinese).

[17] MA Shidong. The analysis of the rotor jam faults on ASN axial flow fans with adjustable rotor blade [J]. Heilongjiang Electric Power, 2010(5): 393-398 (in Chinese).

[18] REN Jian. The experimental study of forced fans in power plantboiler [J]. North China Electric Power, 2014(12): 32-36 (in Chinese).

[19] LIU Jiayu, WANG Baohua, YUE Jiaquan. The study of integration reform of induced fans and booster fans in $1000 \mathrm{MW}$ power unit. Thermal Power Generation, 2010(8): 51-56 (in Chinese).

[20] ZHENG Jin. Report of Energy Conversation, stall diagnosis and reform scheme of induced fans of №1generator unit in Huaneng Tongchuan Power Plant [R]. Xi'an: Xi'an Thermal Power Research Institute Co., Ltd. 2010: 7-12 (in Chinese). 